УДК 625.42:625.143

\title{
ЗАКОНОМІРНОСТІ ЗНОШЕННЯ СПОЛУЧЕННЯ "КРОМКА ПІДОШВИ РЕЙКИ - РЕБОРДА ПІДКЛАДКИ"
}

К-т техн. наук О.О.Овчинніков

\section{ЗАКОНОМЕРНОСТИ ИЗНОСА СОПРЯЖЕНИЯ "КРОМКА ПОДОШВЫ РЕЛЬСА -} РЕБОРДА ПОДКЛАДКИ"

К-т техн. наук А.А.Овчинников

\section{"RAIL EDGE - BASEPLATE LEDGE" LINKING WEARING MECHANISM'S MATHEMATICAL FORMULATION}

Cand. of techn. sciences O.Ovchinnicov

На основі аналізу умов роботи сполучення "кромка підошви рейки - реборда підкладки" в кривих ділянках колї метрополітену визначено характер прочесів, щзо протікають у зоні контакту, та їх влив на режим роботи сполучення. Визначені закономірності ичих процесів та побудовані моделі, щзо показують характер процесу зношення. На основі отриманих результатів прораховано моделі для одно- та багаторазового використання мастила. 


\section{Ключові слова: мастило, зношення, кромка підошви рейки, реборда підкладки}

На основании анализа условий работи сопряжения "кромка подощвы рельса - реборда подкладки" в кривых участках пути метрополитена определен характер прочессов, протекающих в зоне контакта, и их влияние на режим работы сопряжения. Опредены закономерности этих процессов и построены модели, которые показывают характер прочесса износа. На основе полученных результатов просчитаны модели для одно- и многоразового использования смазки.

Ключевые слова: смазка, износ, кромка подошвы рельса, реборда подкладки.

The character of the processes, taking place in a contact zone and their influence on the working mode of conjugation has been determined on the basis of the analyses of working conditions of "rail base edge - baseplate flange» conjugation. Factors, affecting the conjugation, are devided into two groups. The mechanisms, of the given processes, have been determined depending on the featuchers of each group and models, which show the character of wear process, have been build. The dependances, among the factors, affecting the "rail base edge - baseplate flange» conjugation and random character conditions, such as the topography of contact surfaces, environmental conditions, normal loadings, amplitude, vibration frequency, the change of operational characteristics of lubricant in the corse of time, have been determined. The latent period is limited in the process of conjugation usage, because of different phisicschemical processes of additive molecule destruction take place. These processes benefit to the destruction of lubricant film, i.e. to the mechanical kind of wear. Time period of additive performance till the period of catastrophical wear under the condition of lubrication is characterised by the criterion of fretting proofness.

While developing the model of «rail base edge - baseplate flange» conjugation destruction, the frequency of lubricant introduction is a key question. As a result - the frequency of lubrication introduction determines the life cycle of the considered conjugation.

Being guided by the obtained results, after a complex of analyses had place, the models of one and multi usable applications of lubrication have been calculated.

Keywords: railway, underground, baseplate's flange wear, friction, fretting proofness, lubrication.

Вступ. Проблема зношення підрейкових підкладок у кривих ділянках колії метопролітену гостро постає на протязі останніх декількох років. Виробництва таких елементів верхньої будови колії відсутні на территорії Украіни. Закупівля їх за кордоном стає все більш проблематичною. Зважаючи на інтенсивність виникнення критичного уширення колії, що потребує обов'язкової та термінової заміни підрейкових підкладок у кривих ділянках колії внаслідок зношення їх упорних реборд приблизно через $6 \div 8$ місяців експлуатації, виникає необхідність пошуку методів стримування інтенсивності зношення.

Мета дослідження. Для досягнення поставлених цілей на практиці необхідно визначити параметри, фактори та закономірності розвитку та протікання процесів зношення у зоні контакту кромки підошви рейки та реборди підкладки.
Аналіз останніх досліджень i публікацій. Позитивний вплив змащення на уповільнення зношення металевих пар тертя визначено в численних роботах відомих авторів як при експлуатації машин і механізмів [1, 2, 3, 4 та ін.], так і в колійному господарстві в сполученні «колесо - рейка» $[5,6,7,8,9,10$ та ін.]. На підставі аналізу існуючих уявлень про природу фреттинг-корозії та методів захисту від неї можна можна дійти висновку, що з великої кількості розроблених методів захисту від фреттинг-корозії, стосовно умов експлуатації системи «рейка - підкладка», 3 метою уповільнення розвитку такого процесу в сполученні «кромка підошви рейки - реборда підкладки», доцільно використовувати консистентне мастило, яке дозволяє екранувати силові поля поверхонь тертя від впливу навколишнього середовища (зменшити 
корозійну складову), знизити силу тертя i, як результат, зменшити зношення поверхонь тертя.

Основна частина. Найбільш поширеною як теоретична модель зношення багатьох сполучень $є$ закономірність, запропонована В.Ф. Лоренцом, яка одержала назву «крива Лоренца». Однак у результаті аналізу численних експериментальних досліджень отримано класифікацію можливих варіантів залежності зношення від тривалості роботи пар, що труться. Така класифікація передбачає різні характеристики зміни кривої інтенсивності зношення в часі. Як правило, такі криві зношення в часі встановлюють шляхом проведення лабораторних, стендових i експлуатаційних досліджень. Ця обставина обумовлена впливом великої кількості різних параметрів на процес зношення, й у чистому аналітичному вигляді встановити закономірність зношення дуже складно, тому вплив безлічі параметрів можна умовно розділити на дві групи:

Перша група відноситься до невипадкових детермінованих процесів. До таких параметрів стосовно розглянутого сполучення можна віднести: нормальне навантаження; амплітуду й частоту коливань; топографію поверхні. Знаючи характер зміни кожного $з$ перерахованих параметрів у часі, можна побудувати орієнтовну криву зношення розглянутого сполучення.

Однак процес зношення сполучення залежить i від цілого ряду випадкових параметрів (друга група). До них відносяться: нестаціонарний режим роботи розглянутого сполучення; зміна властивостей його поверхонь тертя; вплив навколишнього середовища; зміна експлуатаційних властивостей мастильного матеріалу у часі тощо. Через це завдання визначення закономірностей зношення сполучення «кромка підошви рейки - реборда підкладки» 3 урахуванням випадкових факторів $\epsilon$ надзвичайно важким. Тому на першому етапі дослідження для математичного опису механізму зношення розглянутого сполучення доцільно абстрагуватися від урахування випадкових факторів, тобто доцільно скористатися детермінованою моделлю зношення. Вона дозволить установити закономірність зношення розглянутого сполучення, що послужить основою для прогнозування його ресурсу в експлуатаційних умовах. Закономірність зношення такого реального сполучення найкраще апроксимувати за допомогою ступеневої функції, що враховує вплив основних факторів, які визначають механізм його зношення (рис. 1).

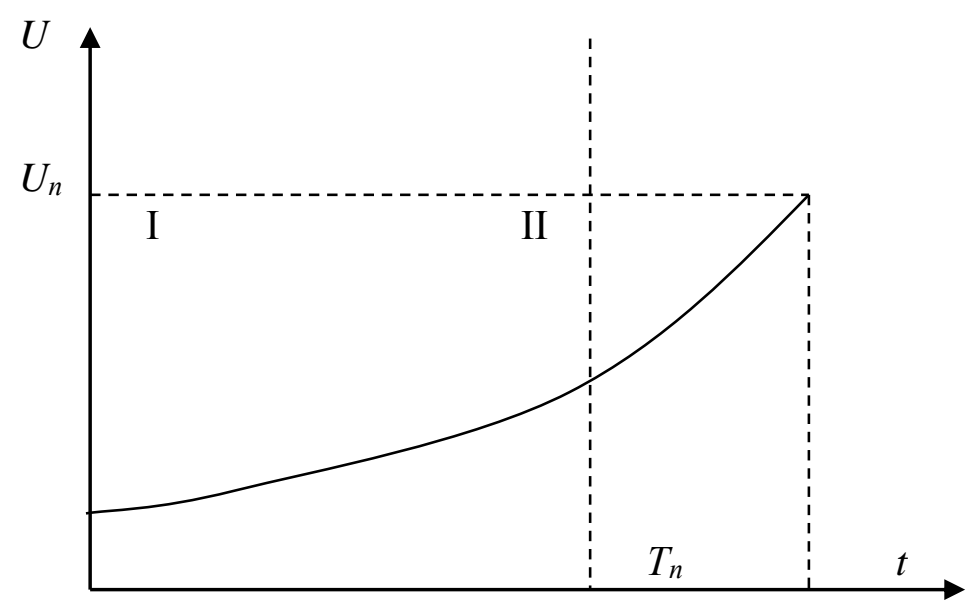

Рис. 1. Закономірність зношення без змащувального матеріалу: I - зона сталого процесу зношення; II - зона катастрофічного зношення розглянутого сполучення 


\section{Примітка. $U_{n}-$ гранично допустиме} зношення сполучення, що регламентує безпеку руху поїздів на криволінійних ділянках колії.

Такий процес можна описати кривою зношення [5]

(1)

$$
U(t)=a+b \cdot t^{\alpha}
$$

де $\quad a$ i $b-$ постійні коефіцієнти, що залежать від режиму роботи розглянутого сполучення.

Коефіцієнт $a$ характеризує процес припрацювання сполучення, ним можна знехтувати, тому що в основі життєвого циклу сполучення розглядається сталий період, а процес припрацювання сполучення, відповідно до численних досліджень [2, 4], становить від життєвого циклу 1 - 2\%. На підставі такого допущення ресурс сполучення визначиться за залежністю

$$
T_{n}=\left(U_{n} / b\right)^{\frac{1}{\alpha}},
$$

Приймаючи до уваги основні фізичні процеси, розглянуті раніше [11], що протікають у досліджуваному сполученні, то в якості критерії оцінки зношення сполучення у часі можна використати фреттингостійкість. Для другого варіанту, коли змащувальний шар у сполученні видавлюється із зазору, залежність прирощення зносу у часі буде залежати від періодичності

поповнення

сполучення компонентом змащення.

Тепер розглянемо випадок одноразового використання змащувального матеріалу в сполученні «кромка підошви рейки - реборда підкладки». Як критерій приймаємо період сталого процесу, що визначається критерієм фреттингостійкості, тобто до стадії, коли мастильний матеріал перестав виконувати своє функціональне призначення. Якщо розглядати варіант сполучення «кромка підошви рейки реборда підкладки» без урахування технологічних факторів, вираз (2) [10] можна спростити, приймаючи такі допущення:

- тривалість латентного періоду головним чином визначається впливом топографії поверхонь тертя;

- нормальне навантаження (максимальне значення) є постійним;

- частота коливань також перебуває в постійному режимі, тобто не змінюється;

- амплітуда коливань відповідає сталому режиму експлуатації сполучення.

3 урахуванням прийнятих допущень вираз (2) [10] набуде вигляду

$$
\Delta t_{1}=k_{1} \cdot R_{a} \cdot e^{\alpha_{1}}
$$

Закономірність зміни зношення сполучення в часі для процесу експлуатації можна представити в наступному вигляді (рис. 2).

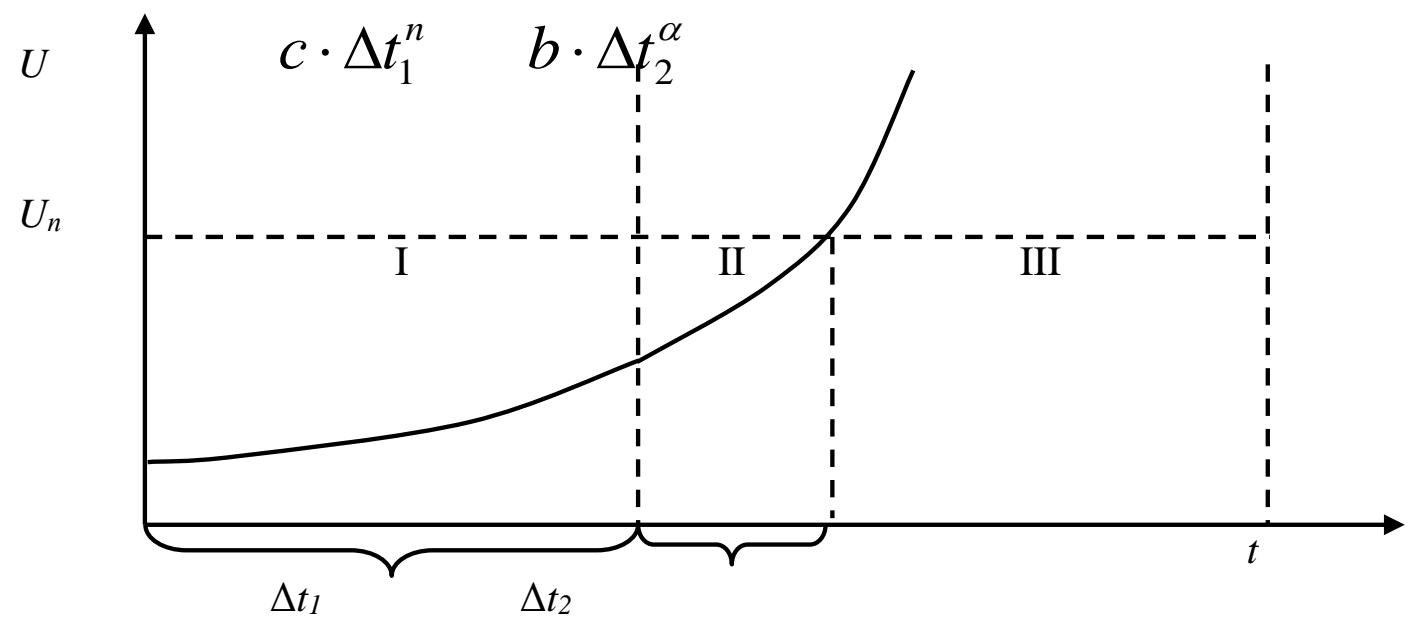

Рис. 2. Закономірність зміни зношення сполучення у випадку одноразового використання мастила в розглянутому сполученні: I - зона наявності змащувального матеріалу; II - зона відсутності змащувального матеріалу; III - зона катастрофічного зношення 
Такий варіант використання змащення поверхонь тертя приведе до істотного загальмування зношення на ранній стадії його розвитку, а закономірність зміни зношення надалі (після закінчення латентного періоду) буде близькою до варіанта відсутності мастильного середовища. Зменшення зношення буде властивим тільки початковому періоду експлуатації сполучення, тому характер кривої зношення в цілому відрізняється від варіанта відсутності мастильного матеріалу в сполученні.

Величина гранично допустимого зношення буде описуватися двома зонами: I присутність мастильного матеріалу; II відсутність мастила.
У загальному вигляді крива зношення до граничнодопустимої величини буде описуватися виразом, що складається із двох складових:

$$
U(t)=c \cdot \Delta t_{1}^{n}+\boldsymbol{B} \cdot \Delta t_{2}^{\alpha},
$$

де $c, n-$ коефіцієнти, для режиму граничного змащення;

в, $\alpha$ - коефіцієнти, що відповідають режиму відсутності мастила.

Тут слід відмітити, що величина $\Delta t_{1}$ (тривалість першого періоду) визначається латентним періодом, критерієм фреттингостійкості, тоді вираз (4) 3 урахуванням формули (2) [10] набуде вигляду:

Якщо відомо значення граничного зношення $U_{n}$, як і в попередньому випадку, то ресурс сполучення визначається розв'язанням

$$
\left\{\begin{array}{l}
U_{n}=c \cdot\left(k_{1} \cdot R_{a} \cdot e^{\frac{-k_{2} \cdot A \cdot N \cdot f}{R_{a}}}\right)^{n}+b \cdot \Delta t_{2}^{\alpha} \\
T_{p}=\Delta t_{1}+\Delta t_{2}
\end{array} .\right.
$$

системи рівнянь. Згідно графіка зміни зношення сполучення (рис. 2) $T=\Delta t_{1}+\Delta t_{2}$, тому маємо

3 урахуванням припущень

$$
\left\{\begin{array}{l}
U_{n}=c \cdot\left(k_{1} \cdot R_{a} \cdot e^{\alpha_{1}}\right)^{n}+b \cdot \Delta t_{2}^{\alpha} \\
T_{p}=\Delta t_{1}+\Delta t_{2}
\end{array} .\right.
$$

Для розв'язання системи рівнянь (7) необхідно знати деякі значення коефіцієнтів $c$, $k_{l}, \quad b, \quad \mathrm{i} \quad \alpha, \alpha_{1}, \quad$ що визначаються 3 експериментальних досліджень.

Перейдемо до розгляду варіанта періодичного (багаторазового) використання мастил у сполученні «кромка підошви рейки реборда підкладки». В основу моделі зношення при періодичному поповненні мастилом поверхонь тертя сполучення покладено припущення, що 3 початку його експлуатації мастило наявне. Зношення на початковій стадії підкоряється основним закономірностям, властивим режиму граничного змащення. Такий механізм зношення утворенням найтонших шарів мастил на поверхнях тертя завдяки наявності поверхневоактивних речовин у мастилі, силовому полю поверхні тертя й конкурентним абсорбційним процесам. Товщина такої плівки, залежно від умов навантаження, складається 3 безлічі моношарів. Найбільш висока несуча спроможність їі спостерігається, коли за своєю товщиною вона наближається до критичного значення, або приблизно становить, відповідно до численних досліджень, до 0,1 мкм. Характерна риса такого процесу (граничного змащення) - в'язкість мастила (об’ємна), не 


\section{Будівельні матеріали, конструкції та споруди}

надає істотного впливу на процес тертя. Ї̈̈ прояв виявляється лише в тому, що при вібраціях зайве мастило витискається із зони контакту, а на поверхні тертя перебувають тільки адсорбовані молекули поверхнево-активних речовин (присадок). Гідродинамічний ефект цього режиму змащення малоймовірний.

Доцільно розглянути закономірність зношення у режимі, коли зовнішне навантаження не перевищує межі міцності несучої спроможності граничної плівки. Однак у процесі експлуатації сполучення латентний період $\epsilon$ обмеженим, тому що відбуваються різні фізико-хімічні процеси (деструкція молекул присадки та ін.), що сприяють руйнуванню мастильної плівки, тобто через певний час пара тертя переходить до варіанту взаємодії силових полів поверхонь тертя, тобто до механічного виду зношення. Такий вид зношення в умовах фреттинг-корозії приводить до інтенсивного руйнування поверхонь тертя. Інтервал часу дії присадки до періоду катастрофічного зношення в умовах змащення характеризується критерієм фреттингостійкості. При розробці моделі спрацювання сполучення «кромка підошви рейки - реборда підкладки» ключовим питанням є періодичність введення мастила, що в остаточному підсумку й визначає ресурс розглянутого сполучення.

Закономірність такого варіанта зношення сполучення можна представити у вигляді схеми (рис.3).

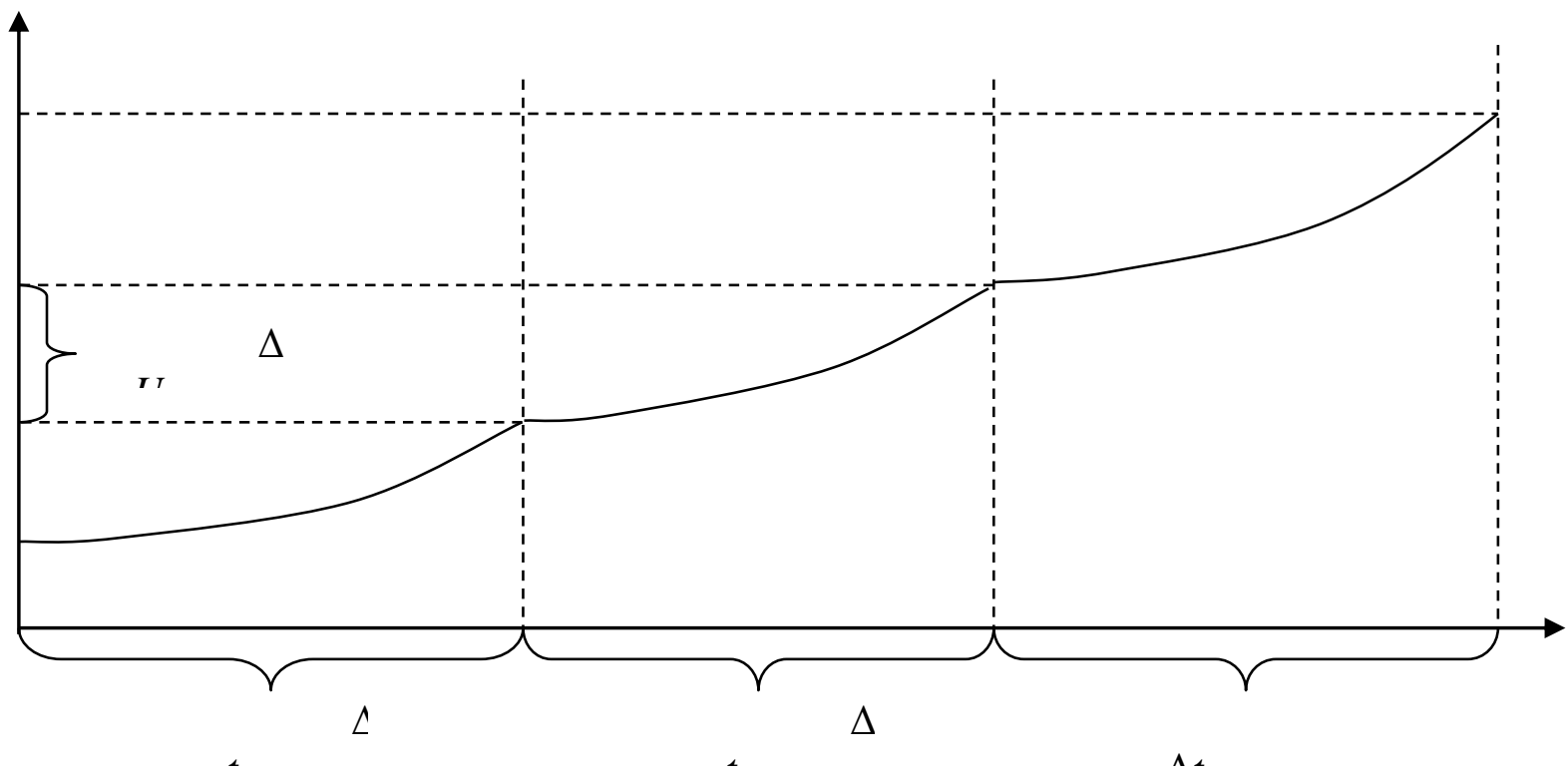

Рис. 3. Закономірність зношення сполучення «кромка підошви рейки - реборда підкладки» при періодичному введенні мастила

Математичний опис такого варіанта змащення буде мати вигляд:

$$
\begin{gathered}
T_{p}=\Delta t_{1}+\Delta t_{2}+\Delta t_{3}+\ldots+\Delta t_{\mathrm{n}}, \\
T_{p}=\frac{U_{n}}{\Delta U_{i}} \cdot t_{3 . M .}, \quad \text { (9) }
\end{gathered}
$$

За умов рівності $\Delta t_{1}=\Delta t_{2}=\ldots=\Delta t_{n}=t_{3 м}$ :

$$
T_{p}=t_{\text {зм.i }} \cdot n \text {, }
$$

$$
T_{p}=\frac{U_{n}}{\Delta U_{i}} \cdot t_{\text {зм. }}
$$

де $t_{3 м}$. час між введеннями мастила (періодичність змащення);

$U_{n-}$ гранично допустима величина зношення реборди підкладки;

$\Delta U_{i}-$ зношення реборди в період між введенням мастила. 


\section{Будівельні матеріали, конструкції та споруди}

Аналізуючи умови роботи сполучення «кромка підошви рейки - реборда підкладки», можна дійти таких висновків:

1. На умови роботи упорних реборд підрейкових підкладок $\mathrm{y}$ кривих ділянках метрополітену впливають: амплітуда та частота коливань, топографія поверхні, навколишнє середовище.
2. На основі закономірностей зношення при багаторазовому введенні мастил до сполучення «кромка підошви рейки - реборда підкладки» ключовим питанням залишається періодичність введення мастил, та на його основі, визначення ресурсу сполучення, що розглядається.

\section{Список використаних джерел}

1. Алябьев А.Я. Методы защиты деталей от фреттинг-коррозии / А.Я. Алябьев // Надежность и долговечность авиационных газотурбинных двигателей: сб. науч. тр. -Киев: изд-во КИИГА. - Вып. 1. - 1971. - С. 58-62.

2. Голего Н.Л. Исследование механизма фреттинг-коррозии / Н.Л. Голего и др. // Проблемы трения и изнашивания: сб. науч. тр. - Вып. 1. - К.: Техника, 1971. - С. 119-127.

3. Зорин В.А. Основы работоспособности технических систем: учебник для вузов / B.A. Зорин. - М.: ООО «Магистр-Пресс», 2005. - 536 с.

4. Голего Н.Л. Фреттинг-коррозия металлов / Н.Л. Голего, А.Я. Алябьев, В.В. Шевеля Киев: Техника, 1974. - 272 с.

5. Карпущенко Н.И. Смазка - единственный способ предупреждения износа / Н.И. Карпущенко // Путь и путевое хозяйство.- 2000.- №2- С. 15-18.

6. Сосновский Л.А. Проблема колесо-рельс с позиций трибофатики / Л.А. Сосновский, В.И. Сенько // Железнодорожный транспорт. - 2007. - №3.- С. 38-44.

7. Пути снижения износа колес и рельсов [електронний ресурс] // Железные дороги мира.2002.- №4. - Режим доступу: http://www.zdmira.com

8. Оптимизация взаимодействия колеса и рельса [електронний ресурс] // Железные дороги мира. - 2003. - №1. - Режим доступу: www.zdmira.com

9. Смазывание гребней бандажей и стрелочных переводов на железных дорогах Германии (по материалам отделения трибологии и триботехники компании DB Systemtechnik.) // Железные дороги мира. - 2008. - №8. -С. 74-78.

10. Лисіков Є.М. Фізичні основи процесу зношування в сполученні «підошва рейки реборда підкладки» при змащуванні / Шраменко В.П., Овчинніков О.О. [та ін.] //Зб. наук. праць УкрДАЗТ. - Харків: УкрДАЗТ, 2009. - Вип. 103. - С. 206-210.

Рецензент д-р техн. наук, професор А.А.Плугін

Овчинніков Олександр Олександрович, канд. техн. наук, доцент кафедри колії та колійного господарства Української державної академії залізничного транспорту. Тел. +38(057)7301059.

OvchinnikovOlexandr, cand. techn. sciences, associateprofessorofDepartment "TrackandTrackMaintenance", Ukrainian State Academy of Railway Transport. Tel +38(057)7301059. 